\title{
QUEBRA DE DORMÊNCIA DE VIDEIRAS CV. BENITAKA COM O USO DE HIDROLATO DE PAU-D'ALHO (Gallesia integrifolia) ${ }^{1}$
}

\author{
ALINE JOSÉ MAIA², KÁTIA REGINA FREITAS SCHWAN-ESTRADA², \\ CACILDA MÁRCIA DUARTE RIOS FARIA ${ }^{4}$, VIRLENE DO AMARAL JARDINETTI ${ }^{5}$, \\ RENATO VASCONCELOS BOTELHO ${ }^{6}$
}

RESUMO -Em regiões tropicais, com ajuda da aplicação de produtos químicos para induzir a quebra de dormência, é possível obter duas safras anuais de videira. No entanto, a eficácia da utilização destes produtos é questionável, pois sua alta toxicidade é um fator preocupante. Neste sentido, o objetivo do trabalho foi avaliar o efeito da aplicação do hidrolato obtido de pau-d'alho (Gallesia integrifolia) na brotação, produtividade e atividade das enzimas peroxidase e catalase em videiras cv. Benitaka. O experimento foi conduzido em vinhedo comercial no município de Marialva, Estado do Paraná, Brasil, em dois ciclos consecutivos: 2011, de agosto a dezembro, e 2012, de janeiro a julho. Os tratamentos consistiram nas seguintes doses de hidrolato de pau-d'alho: $0 ; 50 ; 100 ; 150$ e $200 \mathrm{~mL} \mathrm{~L}^{-1}$, além da testemunha positiva com cianamida hidrogenada a $20 \mathrm{~mL} \mathrm{~L}^{-1}$. Foram avaliadas as variáveis: porcentagem de gemas brotadas, número de cachos, peso dos cachos, produtividade $\left(\mathrm{t} \mathrm{ha}^{-1}\right)$, atividade das enzimas catalase e peroxidase, e teor de açúcares redutores nas gemas. Na porcentagem de gemas brotadas, houve efeito quadrático em função das doses do hidrolato de pau-d'alho com máxima brotação estimada para as doses de 108,8 e $97 \mathrm{~mL} \mathrm{~L}^{-1}$ de hidrolato de pau-d'alho para o primeiro e segundo ciclos, respectivamente, com resultados semelhantes ao tratamento-padrão com cianamida hidrogenada. Os tratamentos com hidrolato de pau-d'alho também incrementaram o número e o peso dos cachos e a produtividade, apresentando também efeito quadrático em função das doses. Verificouse, ainda, redução da atividade das enzimas catalase, peroxidase e para os teores de açúcares redutores nas gemas para as plantas tratadas com hidrolato de pau-d'alho, evidenciando seu modo de ação via injúrias oxidativas, similarmente ao efeito do tratamento convencional com cianamida hidrogenada. Com base nos resultados obtidos, o hidrolato de pau-d'alho, nas doses entre 100 e $150 \mathrm{~mL} \mathrm{~L}^{-1}$, pode ser uma alternativa para a quebra de dormência de videiras cv. Benitaka em regiões tropicais para a viticultura sustentável.

Termos para indexação: Vitis vinifera, cianamida hidrogenada, brotação, sustentabilidade, produtividade.

\section{BUD BREAK OF 'BENITAKA' GRAPEVINES TREATED WITH Gallesia integrifolia HYDROLATE}

\begin{abstract}
In tropical regions, with the help of applying chemicals to induce dormancy, it is possible to obtain two grapevine annual harvests. However the effectiveness of the use of these products is questionable because of its high toxicity is a concern. In this sense, the objective of this study was evaluate the effect of a hydrolate obtained from Gallesia integrifolia in the sprouting, yield and enzyme activity of peroxidase and catalase on grapevines 'Benitaka'. The experiment was realized in commercial vineyard in the city of Marialva, state of Paraná, Brazil, in two consecutive cycles: 2011, August to December and 2012, January to July. The treatments consisted of the following doses of Gallesia hydrolate: $0,50,100,150,200 \mathrm{~mL} \mathrm{~L}^{-1}$, besides the positive control with hydrogen cyanamid to $20 \mathrm{~mL} \mathrm{~L}^{-1}$. It was evaluated the following variables: percentage of sprouting, number of clusters, cluster weight, yield $\left(\mathrm{t} \mathrm{ha}^{-1}\right)$, activity of catalase and peroxidase and content of reducing sugars in the buds. For the percentage of sprouting, there was a quadratic effect depending on the doses of Gallesia hydrolate with budburst estimated maximum doses of 108.8 and $97 \mathrm{~mL} \mathrm{~L}^{-1}$ of hydrolate for the first and second cycle, respectively, with similar results to treatment with hydrogen cyanamid. Treatments with Gallesia hydrolate also increased the number and the mass of clusters and the yield, with a quadratic effect depending on the dose. It was also verified the reduced activity of catalase, peroxidase and for the reduced sugars in the buds for plants treated with Gallesia hydrolate, showing its mode of action via oxidative stress, similar to the effect of treatment with conventional hydrogen Cyanamid. Based on the results obtained the Gallesia hydrolate in the doses between 100 and $150 \mathrm{~mL} \mathrm{~L}^{-1}$ can be an alternative to break dormancy of grapevine 'Benitaka' in tropical regions for sustainable viticulture.
\end{abstract}

Index terms: Vitis vinifera, grapes, sprouts, sustainability, dormancy.

\footnotetext{
1(Trabalho 122-13). Recebido em: 14-03-2013. Aceito para publicação em: 06-09-2013. Parte da tese de doutorado do primeiro autor. ${ }^{2}$ Doutoranda do programa Pós-Graduação em Agronomia-UEM - Maringá-PR - E-mail: alymaia2005@yahoo.com.br ${ }^{3}$ Eng $^{\mathrm{a}}$. Agra . Dr. Prof. associado do Depto. de Agronomia -UEM. Bolsista PQ - E-mail: krfsestrada@uem.br ${ }^{4}$ Enga . Agra . Dr. Prof. Adjunto do Depto. de Agronomia /UNICENTRO - Guarapuava-PR E-mail: criosfaria@hotmail.com ${ }^{5}$ Mestranda do programa de Pós- Graduação em Agronomia/UEM - E-mail: vir_agro@hotmail.com

${ }^{6}$ Eng. Agr. Dr. Prof. Adjunto do Depto. de Agronomia/ UNICENTRO, Setor Fruticultura. E-mail: rbotelho@unicentro.br
} 


\section{INTRODUÇÃO}

Um dos fatores limitantes na produção de uvas em regiões de clima tropical é a dormência das gemas, visto que nestas regiões somente é possível obter duas safras anuais, com o uso de produtos que promovam a quebra de dormência (KISHINO et al., 2007).

Segundo Or et al. (2000), a ausência de frio invernal na videira produz efeitos adversos, como atraso na brotação das gemas, pouca uniformidade e desenvolvimento dos ramos e atraso na maturação das bagas, promovendo perdas significativas na produção e na qualidade nos frutos e, consequentemente, seu valor comercial. No entanto, condições ambientais favoráveis, tais como temperaturas elevadas, são necessárias para o crescimento das gemas, após concluído o período de dormência (MULLINS et al., 1992). O início do ciclo anual de crescimento está estreitamente relacionado com a temperatura, pois esta atua sobre a velocidade das reações metabólicas que promovem a quebra de dormência das gemas e leva à brotação (CALÒ et al., 1996).

Em substituição à falta de horas de frio, o indutor químico mais utilizado na quebra de dormência das videiras é a cianamida hidrogenada $\left(\mathrm{H}_{2} \mathrm{CN}_{2}\right)$. Sabe-se que esta substância é rapidamente absorvida e metabolizada, e seu modo de ação está relacionado à diminuição da atividade de enzimas envolvidas na rota de formação de espécies reativas de oxigênio. Dentre elas, a enzima catalase (enzima presente em células anaeróbias), que degrada o peróxido de hidrogênio $\left(\mathrm{H}_{2} \mathrm{O}_{2}\right)$ numa molécula de oxigênio $\left(\mathrm{O}_{2}\right)$ e uma de água $\left(\mathrm{H}_{2} \mathrm{O}\right)$, o que resulta em um aumento da concentração de peróxido de hidrogênio $\left(\mathrm{H}_{2} \mathrm{O}_{2}\right)$ nas gemas (GOLDBACK et al., 1988). Esse aumento é responsável pela ativação do ciclo das pentoses e consequente indução da saída da dormência das gemas (OMRAN, 1980).

No entanto, este composto é classificado como altamente tóxico ao ser humano (categoria I). De acordo com Settimi et al. (2005), a cianamida hidrogenada pode provocar ulcerações nos olhos, pele e trato respiratório, além de inibir a aldeído desidrogenase, levando à síndrome de acetaldeído. Esta síndrome é caracterizada por vômito, hiperatividade parassimpática, dispneia, hipotensão e desorientação. Esse alto risco de intoxicação pela exposição à cianamida hidrogenada levou à suspensão temporária das vendas do produto comercial Dormex ${ }^{\circledR}$, em 2002, na Itália, e revisão de sua regulamentação pelas autoridades da União Europeia. Desde 2008, a cianamida hidrogenada não pode ser comercializada nos países da Europa
(SETTIMI et al., 2005).

No Brasil, produtos naturais, como o extrato de alho (Allium sativum), têm sido utilizados na superação da dormência em fruteiras de clima temperado, em sistemas de produção orgânica, principalmente para a viticultura (BOTELHO et al., 2007). Sua atividade biológica está relacionada à presença de compostos voláteis contendo enxofre e um grupo alil $\left(\mathrm{CH}_{2} \mathrm{CHCH}_{2}\right)$, particularmente dialil dissulfito (KUBOTA et al., 1999).

Em trabalho desenvolvido por Sanchez (1992), verificou-se que misturas de óleo mineral a $4 \%$ com extrato de alho a $2 ; 4$ ou $8 \%$, resultaram nos tratamentos mais efetivos para incrementar a brotação das gemas floríferas de ameixeiras cv. Santa Rosa, quando comparados com cianamida. No entanto, que Botelho et al. (2007), com o objetivo de desenvolver um método alternativo para a quebra de dormência de gemas de macieiras 'Fuji Kiku', utilizaram extrato de alho e verificaram que sua mistura em concentrações entre 1 e $10 \%$ com óleo mineral a $2 \%$ apresentou efeito similar ao tratamento convencional com cianamida hidrogenada.

Kubota e Myamuki (1992) verificaram que a aplicação de pasta de alho na região do corte de poda de ramos de videiras 'Moscatel de Alexandria' estimulou a brotação de gemas de forma mais efetiva que a aplicação de solução a $20 \%$ de calciocianamida $\left(\mathrm{CaCN}_{2}\right)$, produto tradicionalmente utilizado na viticultura japonesa para esta finalidade. Resultados satisfatórios na quebra de dormência foram observados por Botelho et al. (2010), quando utilizaram uma solução de $70 \mathrm{~mL} \mathrm{~L}^{-1}$ de extrato de alho em videiras cv. Niagara Rosada (Vitis labrusca).

No entanto, o extrato de alho apresentou resultados satisfatórios na quebra de dormência em videiras, considerando que seu centro de origem é nas zonas temperadas da Ásia Central, mas no Brasil apresenta elevado custo de produção e obtenção. $\mathrm{Na}$ busca de alternativas, uma planta que pode ser promissora para obtenção de produtos com efeitos na quebra de dormência é a Gallesia integrifolia, com sinonímia Gallesia gorazema (Vell.) Moq., Crataeva gorazema Vell., pertencente à família Phytolaccaceae, uma vez que ocorre naturalmente em vários estados brasileiros, desde o Estado do Ceará até o Paraná (CARVALHO 1994).

Esta planta é uma espécie arbórea de grande porte, frequente nas florestas pluvial atlântica e estacional semidecidual (DURIGAN et al., 1997). Produz madeira de múltiplo uso, com cheiro característico de alho quando verde, por isso é denominada vulgarmente de pau-d'alho. A madeira perde esse cheiro quando seca e torna-se 
durável, sendo utilizada em substituição ao pinheiro (NOGUEIRA, 1977; CARVALHO, 1994).

Segundo Barbosa et al. (1999), mais de quinze compostos sulfurados foram encontrados em extratos brutos obtidos das folhas e óleo essencial obtido da casca do pau-d'alho. Kubota et al. (1999) sugerem que substâncias voláteis de compostos sulfurados são efetivas na quebra de dormência em videiras. Considerando que do pau-d'-alho utilizam-se somente as folhas para a obtenção do óleo essencial e hidrolato, isso possivelmente incentivaria a produção de populações desta importante espécie arbórea endêmica brasileira (FEITAS et al., 2008).

Neste sentido, o objetivo do trabalho foi verificar os efeitos do hidrolato pau-d'alho $(G$. integrifólia) na quebra de dormência, produtividade e atividade das enzimas peroxidase e catalase de videiras cv. Benitaka.

\section{MATERIAL E MÉTODOS}

O experimento foi realizado em vinhedo comercial sobre um talhão da cultivar Benitaka, localizado no município de Marialva, Paraná (2327'49,86”S, 5147’18,74” O; altitude 614m). O clima da região é classificado como clima tropical, com a temperatura media no mês mais frio inferior a $18^{\circ} \mathrm{C}$ e temperatura média do mês mais quente acima de $22^{\circ} \mathrm{C}$, tipo Cfa (SIMEPAR, 2012).

Plantas da cv. Benitaka de 11 anos de idade, enxertadas sobre o porta-enxerto IAC 752 'Tropical', em espaçamento $2,0 \times 2,5 \mathrm{~m}$, e conduzidas no sistema latada, foram utilizadas para as avaliações. $\mathrm{O}$ experimento foi conduzido durante duas épocas consecutivas, nos ciclos de 2011, de agosto a dezembro (safra), e 2012, de janeiro a junho (safrinha).

Os tratamentos consistiram nas seguintes doses do hidrolato pau-d'alho: 0;50; 100; 150 e 200 $\mathrm{mL} \mathrm{L}^{-1}$. Além disso, foi incluído o tratamento com cianamida hidrogenada a $20 \mathrm{~mL} \mathrm{~L}^{-1}$ (Dormex ${ }^{\mathrm{TM}}$, Basf Co., $520 \mathrm{~g} \mathrm{~L}^{-1}$ i.a.). Utilizaram-se $500 \mathrm{~mL}$ de calda por planta, o equivalente a $74 \mathrm{~L}$ por hectare, até o ponto de escorrimento, aplicados com pulverizador manual, logo após a poda longa (oito gemas), em 1308-11 e 30-01-12, sendo que somente as três primeiras gemas apicais foram pulverizadas. O delineamento experimental foi em blocos casualizados, com cinco tratamentos e quatro repetições, e a parcela experimental, constituída por uma planta.

O hidrolato de pau-d'alho foi obtido por hidrodestilação, a partir de folhas secas ao ar. O conjunto destilador de óleo essencial foi constituído por uma autoclave, do qual sai o vapor que passa pelo cesto contendo dois quilos de folhas secas da respectiva planta e, em seguida, passa pelo condensador e pelo funil de separação, obtendose, no final do processo, o óleo essencial, sendo o hidrolato o subproduto desta extração. A coleta das folhas foi realizada após seu período de floração, no mês de agosto do ano de 2011, de plantas do Câmpus da Universidade Estadual de Maringá-PR.

Foram avaliadas as seguintes variáveis: 1-) porcentagem de gemas brotadas: para isto, aos 21 dias após a pulverização dos tratamentos, foram avaliados cinco ramos por planta, sendo considerada como gema brotada quando esta apresentava a primeira folha expandida; 2-) número de cachos por planta: após o pegamento, no dia da colheita (131 e 143 dias após a aplicação dos tratamentos, na primeira e segunda safras, respectivamente), fez-se a contagem de todos os cachos e da massa dos mesmos (g); produção por planta $\left(\mathrm{kg} \mathrm{planta}^{-1}\right)$ : calculada por meio do número de cachos multiplicado pela massa fresca dos cachos e produtividade estimada $\left(\mathrm{t} \mathrm{ha}^{-1}\right)$.

Para a análise bioquímica, a coleta das gemas foi realizada 24 horas após a aplicação dos tratamentos, na primeira e na segunda safras, nas primeiras horas da manhã. As gemas foram envolvidas em papel-alumínio, colocadas em caixas de isopor com gelo em escamas e transportadas ao laboratório, onde ficaram armazenadas a $-20{ }^{\circ} \mathrm{C}$, em freezer, até o momento da maceração das mesmas. $\mathrm{O}$ extrato enzimático foi obtido por meio da maceração de quatro gemas de cada planta $(0,3 \mathrm{~g}), \mathrm{com} \mathrm{N}_{2}$ líquido e homogeneizado em almofariz com $4 \mathrm{~mL}$ de tampão fosfato de potássio $50 \mathrm{mM}$ (pH 7,0), contendo 0,1 mM EDTA e $1 \%(\mathrm{p} / \mathrm{p})$ de PVP (polivinilpirrolidona). O extrato obtido foi centrifugado a $7.300 \mathrm{~g}$ a $4{ }^{\circ} \mathrm{C}$, durante $30 \mathrm{~min}$, e o sobrenadante foi armazenado a $-20{ }^{\circ} \mathrm{C}$ até a realização dos ensaios.

A atividade da peroxidase de guaiacol (EC 1.11.1.7) foi realizada segundo Lusso e Pascholati (1999), medindo a conversão do guaiacol em tetraguaiacol. A mistura da reação continha $1 \mathrm{~mL}$ do extrato enzimático e $2,0 \mathrm{~mL}$ da solução com 250 $\mu \mathrm{L}$ de guaiacol ( $97 \%$ ) $306 \mu \mathrm{L}$ de peróxido de hidrogênio (34\%), em $100 \mathrm{~mL}$ de tampão fosfato $0,01 \mathrm{M}(\mathrm{pH} 6,0)$, e a mistura ficou em banho- maria a $30^{\circ} \mathrm{C}$. A atividade da peroxidase foi determinada através de método espectrofotométrico direto, a 470 $\mathrm{nm}$, por um período de $2 \mathrm{~min}$, com leituras a cada 10 segundos. O diferencial entre a leitura aos $100 \mathrm{~s}$ e a leitura aos $40 \mathrm{~s}$ foi utilizado para a determinação da atividade, pois este foi o período de maior atividade na leitura. Os resultados foram expressos em absorbância $\min ^{-1} \mathrm{mg}^{-1}$ de proteína.

A atividade da catalase (EC 1.11.1.6) foi 
quantificada pelo método de Góth (1991), modificado por Tomanková et al. (2006), através da formação de um complexo estável entre o molibdato de amônio e o peróxido de hidrogênio (A405). O extrato enzimático $(0,2 \mathrm{~mL})$ foi incubado em $1 \mathrm{~mL}$ de mistura de reação contendo $60 \mathrm{mM}$ de peróxido de hidrogênio em tampão fosfato de potássio $60 \mathrm{mM} \mathrm{pH} \mathrm{7,4,} \mathrm{a} 38^{\circ} \mathrm{C}$, por $4 \mathrm{~min}$. A adição de $1 \mathrm{~mL}$ de $32,4 \mathrm{mM}$ de molibdato de amônio, após 4 min de incubação, foi feita para deter o consumo de peróxido de hidrogênio pela enzima presente no extrato. Foi preparado um branco para cada amostra através da adição de molibdato de amônio à mistura de reação, omitindo o período de incubação. O complexo amarelo de molibdato e de peróxido de hidrogênio foi medido em espectrofotômetro a 405 nm. A diferença entre a absorbância do branco e a amostra incubada indicou a quantidade de peróxido de hidrogênio utilizado pela enzima. A concentração de $\mathrm{H}_{2} \mathrm{O}_{2}$, foi determinada, utilizando-se do coeficiente de extinção $\epsilon=0,0655 \mathrm{mM}^{-1} \mathrm{~cm}^{-1}$.

A determinação do conteúdo proteico foi realizada conforme Bradford (1976), onde, em 2,5 $\mathrm{mL}$ do reagente de Bradford, foram adicionados 50 $\mu \mathrm{L}$ do extrato enzimático. Após $5 \mathrm{~min}$, foi efetuada a leitura da absorbância a $595 \mathrm{~nm}$ em espectrofotômetro. A concentração de proteínas, expressa em $\mathrm{mg} \mathrm{mL}^{-1}$ de amostra (mg proteína $\mathrm{mL}^{-1}$ ), foi determinada, utilizando-se da curva-padrão de concentrações de albumina de soro bovino (BSA), de 0 a $0,5 \mathrm{mg} \mathrm{mL}^{-1}$. A curva-padrão de albumina de soro bovina obtida pelo método de Bradford foi $\mathrm{y}=-0,0456+0,733 \mathrm{x}$.

Os açúcares redutores foram quantificados pelo método de Lever (1972). O extrato enzimático $(0,250 \mathrm{~mL})$ reagiu com $0,750 \mathrm{~mL}$ de hidrazida do ácido p-hidroxibenzoico a $100{ }^{\circ} \mathrm{C}$ por $5 \mathrm{~min}$; em seguida, a mistura foi resfriada, e sua absorbância a $410 \mathrm{~nm}$ foi determinada em espectrofotômetro. A concentração de açúcares redutores, expressa em $\mu \mathrm{g} \mathrm{mL}^{-1}$ de amostra $\left(\mu \mathrm{g}\right.$ açúcares redutores $\left.\mathrm{mL}^{-1}\right)$, foi determinada utilizando-se da curva-padrão de concentrações de glucose de 0 a $1 \mu \mathrm{g} \mathrm{mL}^{-1}(\mathrm{y}=0,1563+0,957 \mathrm{x} /$ $\mathrm{R}^{2}=0,9991$ ).

Os resultados foram submetidos à análise de variância e, quando significativos, realizouse a comparação de médias, pelo teste Tukey, e análise de regressão polinomial, ao nível de 5\% de probabilidade, através do programa estatístico SISVAR (FERREIRA, 2011).

\section{RESULTADOS E DISCUSSÃO}

Aos 21 dias após os tratamentos, as doses do hidrolato de pau-d'alho apresentaram efeito quadrático para a variável porcentagem de gemas brotadas, em ambas as safras obtidas da dupla poda anual (Figura 1A e 1B). No ano de 2011, a dose estimada para máxima brotação foi de $108,83 \mathrm{~mL}$ $\mathrm{L}^{-1}$ de hidrolato de pau-d'alho, ocorrendo posterior decréscimo com o aumento das doses. A dose de 100 $\mathrm{mL} \mathrm{L}^{-1}$ de hidrolato de pau-d'alho atingiu $46,7 \%$ de brotação e não apresentou diferença significativa em relação ao tratamento com cianamida hidrogenada, que alcançou $55,6 \%$ de brotação, enquanto (a testemunha alcançou apenas $15,6 \%$, de brotação (Figura 1A).

Na segunda safra em 2012, a dose estimada para a máxima porcentagem de brotação foi de $97 \mathrm{~mL} \mathrm{~L}^{-1}$ de hidrolato de pau-d'alho, aos 21 dias após a pulverização (Figura 1B), no entanto não se observaram diferenças significativas entre os tratamentos com 50; 100 e $150 \mathrm{~mL} \mathrm{~L}^{-1}$ de hidrolato de pau-d'alho e com cianamida hidrogenada, pelo teste de Tukey $(\mathrm{P}<0,05)$.

No presente estudo, verificou-se que a brotação das gemas de videira cv. Benitaka foi menos expressiva na safra fora de época (2012), que no ano de 2011. Possivelmente, estes resultados foram influenciados pelas condições climáticas da época. Como a poda foi realizada no final do mês de janeiro, consequentemente a brotação ocorreu no mês que apresentou maior temperatura (atingindo temperatura máxima de $35{ }^{\circ} \mathrm{C}$ e temperatura mínima de $21{ }^{\circ} \mathrm{C}$ SIMEPAR, 2012), e a intensidade luminosa mantevese estável, $400 \mathrm{w} \mathrm{m}^{-2}$, o que possivelmente favoreceu a redução na porcentagem de gemas brotadas.

Não há relatos sobre a utilização do hidrolato de pau-d'alho em fruteiras de clima temperado, mas resultados com aplicação de extrato de alho, também bastante ricos em compostos sulfurados, foram relatados por vários autores (KUBOTA et al., 1999; KUBOTA; YAMANE; TORIU, 2002; VARGAS-ARISPURO; CORRALESMALDONADO; MARTÍNEZ-TÉLLEZ, 2008). Resultados satisfatórios foram verificados por Botelho et al. (2010), quando utilizaram $70 \mathrm{~mL} \mathrm{~L}^{-1}$ de extrato de alho em videiras cv. Niágara Rosada, tendo observado $94 \%$ de gemas brotadas. No entanto, Botelho et al. (2007b) observaram $37 \%$ de brotação de videiras cv. Cabernet Sauvignon quando pulverizadas com extrato de alho a $3 \%$, porém este tratamento foi menos efetivo que a cianamida hidrogenada. 
Por ocasião da maturação tecnológica dos frutos, aos 131 dias após os tratamentos, as doses do hidrolato de pau-d'alho apresentaram efeito quadrático para as variáveis: número de cachos, peso dos cachos e produtividade (Figura 2). Com respeito ao número de cachos por planta, o tratamento com hidrolato de pau-d'alho teve um desempenho inferior ao observado com cianamida hidrogenada; no entanto, a dose de melhor resposta foi de 126,9 $\mathrm{mL} \mathrm{L}^{-1}$ do (Figura 2A). O tratamento com 150 $\mathrm{mL} \mathrm{L}^{-1}$ de hidrolato de pau-d'alho proporcionou aumento de $76 \%$ no peso dos cachos, diferindo-se significativamente do tratamento com cianamida hidrogenada (Figura 2C e 2E). Para a produtividade, verificou-se que a dose de $150 \mathrm{~mL} \mathrm{~L}^{-1}$ de hidrolato de pau-d'alho apresentou maior média $\left(18,6 \mathrm{tha}^{-1}\right)$, não diferindo estatisticamente do tratamento com cianamida hidrogenada, que atingiu 13,3 $\mathrm{tha}^{-1}$ (Figura 2E).

$\mathrm{Na}$ segunda colheita, em 23-06-2012, realizada aos 143 dias após a segunda poda, para as variáveis: número de cachos, massa dos cachos e produtividade, observou-se efeito quadrático em função das doses de hidrolato de pau-d'alho, sendo as doses estimadas como ótimas, de 91; 94 e $94 \mathrm{~mL} \mathrm{~L}^{-1}$, respectivamente. Houve diferenças significativas com o tratamento com cianamida hidrogenada (Figuras 2 B, D, J e H).

Após 24 horas da pulverização com hidrolato de pau-d'alho, verificou-se efeito quadrático para a atividade das enzimas catalase, peroxidase (Figura 3) e açúcares redutores (Figura 4), em função das doses do hidrolato de pau-d'alho. No entanto, na safra de 2011, a enzima catalase apresentou efeito linear negativo (Figura 3A).

Na primeira safra avaliada, na enzima catalase verificou-se que houve redução da atividade de até $93 \%$ com a dose de $200 \mathrm{~mL} \mathrm{~L}^{-1}$ de hidrolato de pau d'alho, quando comparada com a testemunha. Além disso, não apresentou diferença estatística com o tratamento convencional de cianamida hidrogenada, que apresentou redução de $71 \%$ (Figura 3A). Na segunda safra avaliada, o tratamento de menor atividade da enzima catalase foi com a aplicação de cianamida hidrogenada, que apresentou diferenças para todas as doses de hidrolato de pau-d'alho.

Na safra de 2011, o tratamento com aplicação de $150 \mathrm{~mL} \mathrm{~L}^{-1}$ de hidrolato de pau-d'alho apresentou, após 24 horas, redução de $87 \%$ da atividade de peroxidase em relação à testemunha, não diferindo estatisticamente do tratamento com cianamida hidrogenada (Figura 3C). Em 2012, as doses do hidrolato de pau-d'alho apresentaram menor atividade em relação à testemunha, não diferindo estatisticamente do tratamento com cianamida hidrogenada (Figura 3D).

Cabe ressaltar que são raros os trabalhos na literatura sobre a quebra de dormência que envolve a atividade de enzimas utilizando produtos naturais. Entretanto, Wang et al. (1991) verificaram redução na atividade das enzimas catalase e peroxidase em gemas de macieira cv. York Imperial tratadas com Thidiazuron (N-phenyl-N'-1, 2, 3-thiadiazol-5ylurea). No entanto, Bajji et al. (2007) verificaram redução e $50 \%$ na atividade da enzima catalase, enquanto a atividade da ascorbato peroxidase foi alta, mostrando apenas mudanças durante o tempo de armazenamento em rebentos apicais de batata tratadas com peróxido de hidrogênio.

De acordo com Nir et al. (1986), quando as gemas são expostas ao frio e a agentes químicos ou naturais, ocorre a inibição da atividade da catalase, enzima presente em todas as células, cuja principal função é degradar o peróxido de hidrogênio $\left(\mathrm{H}_{2} \mathrm{O}_{2}\right)$, o qual provavelmente induz o término da dormência (Pinto et al., 2012).

Segundo Bartosz (1997), o peróxido de hidrogênio $\left(\mathrm{H}_{2} \mathrm{O}_{2}\right)$, espécie reativa de oxigênio, possivelmente atua como um sinalizador em resposta ao estresse abiótico e biótico; porém, quando ocorre o acúmulo, tornam-se tóxicas à célula. Quando há acúmulo de $\mathrm{H}_{2} \mathrm{O}_{2}$, a planta desencadeia a desintoxicação através de uma sequência de reações relacionadas com a via das pentoses-fosfato, conduzindo a um aumento de $\mathrm{NADH}$, acelerando o metabolismo e induzindo o término da dormência (NIR et al.,1986). Pinto et al. (2007) sugerem que todas estas alterações metabólicas têm como consequência o aumento nos níveis da relação AMP/ATP intracelular, que induz a expressão de proteína-kinases, as quais formam parte do sistema de transferência do sinal que leva ao término da endodormência das gemas. Segundo Scandalios (1994), o $\mathrm{H}_{2} \mathrm{O}_{2}$ é eliminado por catalases e peroxidases. A catalase remove a maior parte do $\mathrm{H}_{2} \mathrm{O}_{2}$, enquanto a ascorbato peroxidase pode detoxificar o $\mathrm{H}_{2} \mathrm{O}_{2}$ que é inacessível para a catalase devido a sua alta afinidade por $\mathrm{H}_{2} \mathrm{O}_{2}$, e a sua presença em vários locais dentro da célula (CREISSEN et al., 1994).

Para açúcares redutores, na safra de 2011, as doses do hidrolato de pau-d'alho não apresentaram efeito significativo (dados não apresentados). No ano de 2012, a dose de $100 \mathrm{~mL} \mathrm{~L}^{-1}$ apresentou o menor teor de açúcares redutores, não diferindo estatisticamente do tratamento com cianamida hidrogenada (Figura 4). Provavelmente, durante a divisão celular das gemas, é necessário muita energia para a manutenção e o funcionamento celular e, 
durante este período, as gemas são centros ativos de consumo de glicose para quando ocorram condições favoráveis e iniciem seu crescimento (PINTO et al., 2012).
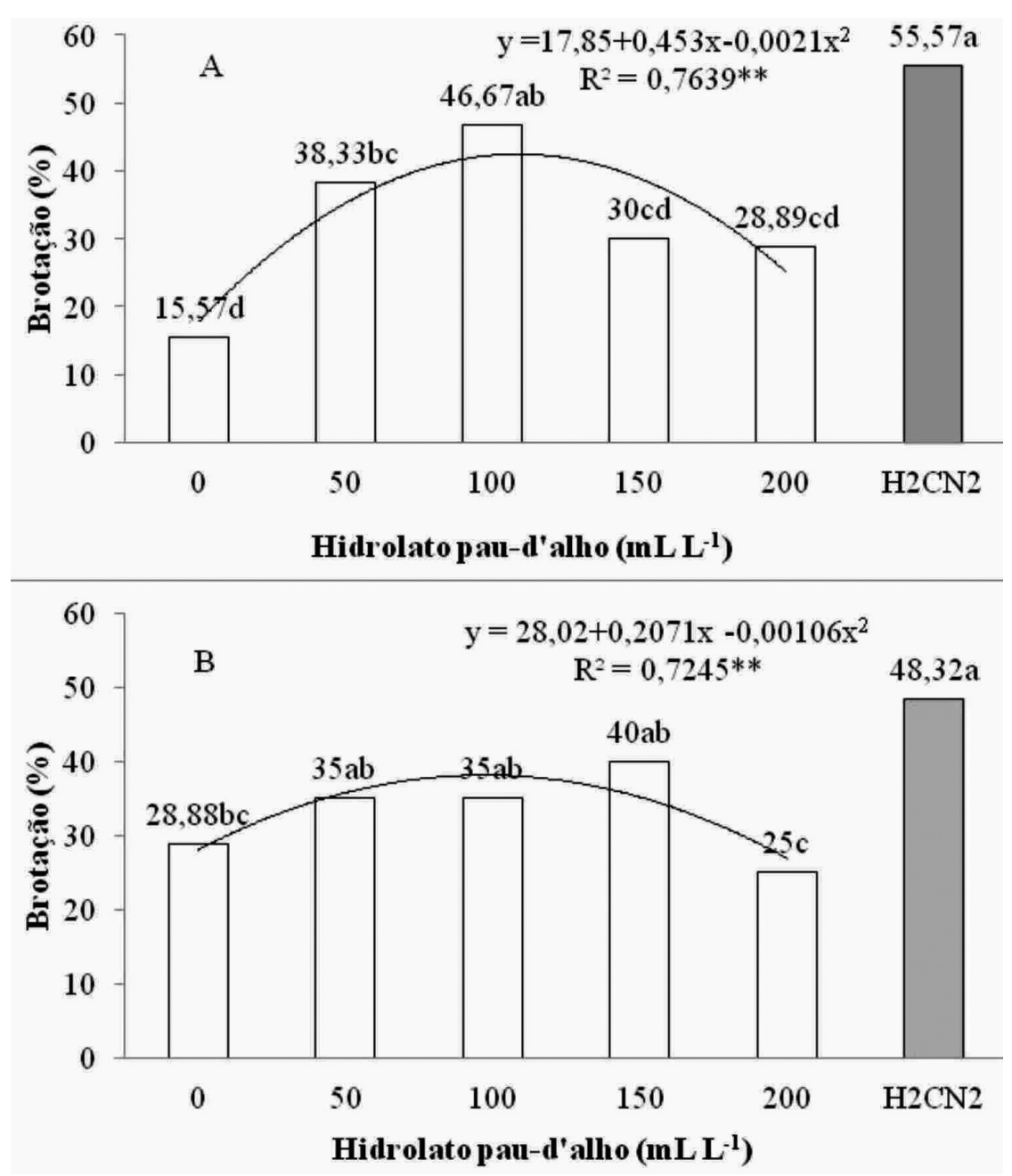

FIGURA 1- Porcentagem de gemas brotadas da cv. Benitaka, submetida a diferentes doses do hidrolato de pau-d'alho, na primeira safra, em 2011 (A) e na segunda safra, em 2012 (B), no município de Marialva-PR. "*Significativo ao nível de $5 \%$ de probabilidade, pelo teste de Tukey 

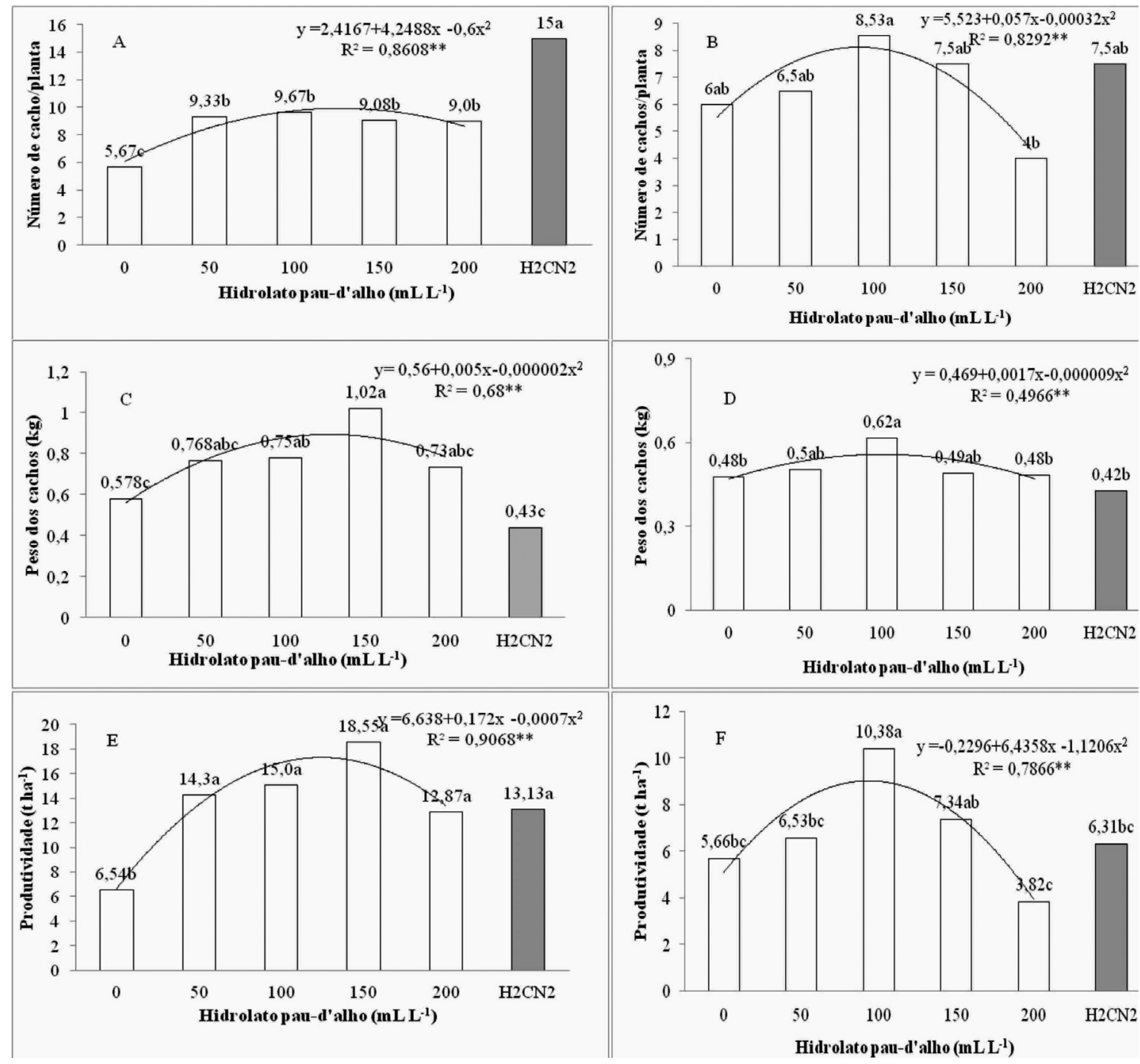

FIGURA 2- Número de cachos, peso médio dos cachos (kg), produção por planta $(\mathrm{kg})$ e produtividade estimada por hectare da cv. Benitaka, submetida a diferentes doses do hidrolato de pau-d'alho, nas safras de 2011(A, C e D) e 2012 (B, E e F), no município de Marialva-PR. "Significativo ao nível de $1 \%$ de probabilidade, pelo teste de Tukey. 

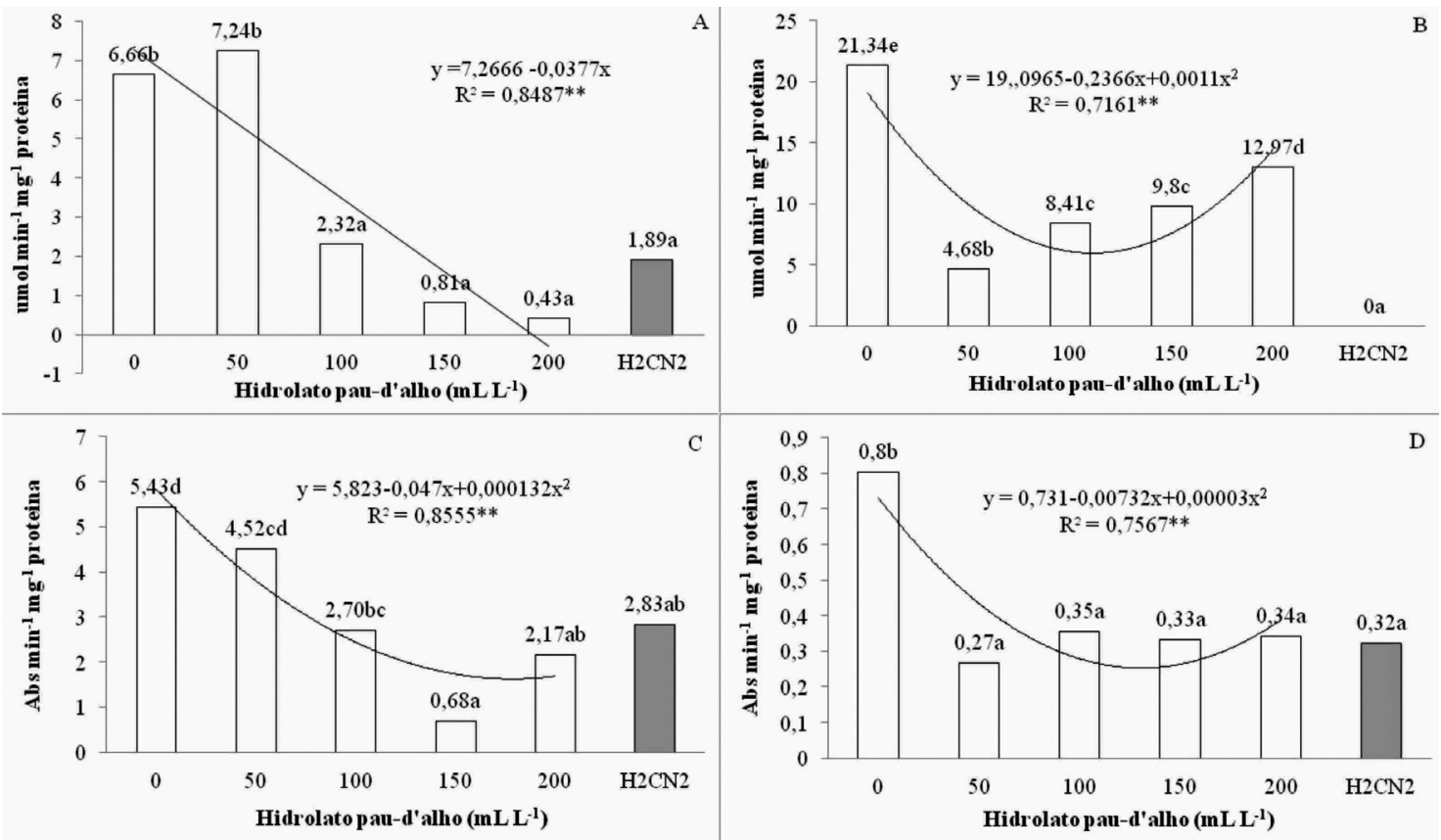

FIGURA 3 - Atividade enzimática de catalase (A e B) e peroxidase (C e D) de gemas de videira cv. Benitaka submetida a diferentes doses do hidrolato de pau-d'alho, nas safras de 2011 (A e C) e 2012 (B e D), no município de Marialva-PR. "Significativo ao nível de $1 \%$ de probabilidade. "significativo ao nível de $5 \%$ de probabilidade,pelo teste de Tukey.

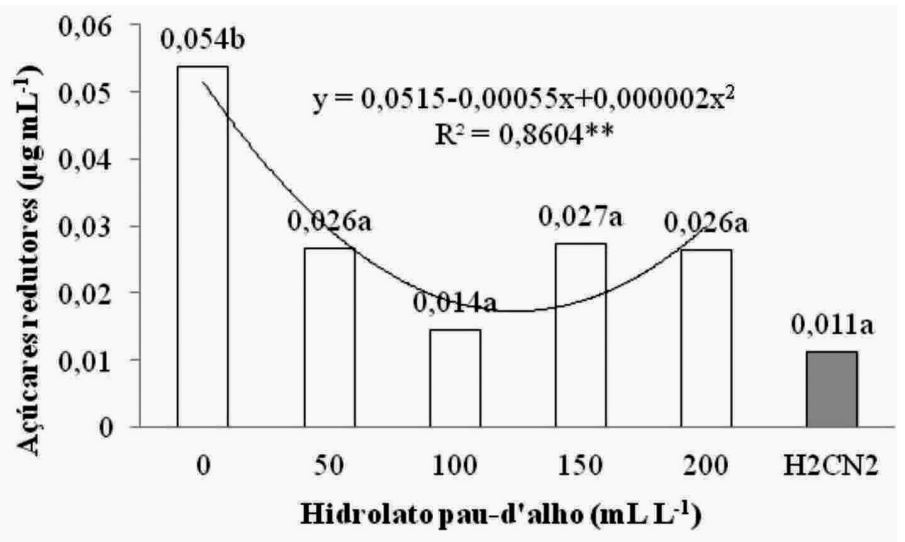

FIGURA 4- Açúcares redutores quantificados pelo método de Lever (1972) de gemas de videira cv. Benitaka submetida a diferentes doses do hidrolato de pau-d'alho, na safra de 2012, no município de Marialva-PR. "Significativo ao nível de $1 \%$ de probabilidade, pelo teste de Tukey

\section{CONCLUSÃO}

O hidrolato de pau-d'alho tem efeito sobre a quebra de dormência de gemas de videiras cv. Benitaka, semelhantes ao tratamento convencional com cianamida hidrogenada, produzindo aumento no número de gemas brotadas e também aumento na produtividade. O hidrolato de pau-d'alho, em doses entre 100 e $150 \mathrm{~mL} \mathrm{~L}^{-1}$, é uma alternativa promissora para o manejo de videiras cv. Benitaka, principalmente para sistemas de produção orgânica. 


\section{AGRADECIMENTOS}

À Coordenação de Aperfeiçoamento de Pessoal de Nível Superior, pela bolsa concedida ao primeiro autor.

\section{REFERÊNCIAS}

BAJJI, M.; M'HAMDI, M.; GASTINY, F.; ROJASBELTRAN, J.A.; JARDIN, P. D. Catalase inhibition accelerates dormancy release and sprouting in potato (Solanum tuberosum L.) tubers. Biotechnologie Agronomie Société et Environnement, Liège, v. 11, n. 2, p. 121-131, 2007.

BARBOSA, L.C.A.; DEMUNER, A.J.; TEIXEIRA, R.R.; MADRUGA, M.S. Chemical constituents of the bark of Gallesia gorazema. Fitoterapia, Milano, v.70 n.2, p. 152-156, 1999.

BARTOSZ, G. Oxidative stress in plants. Acta Physiologiae Plantarum, Kraków, v. 19, n. 1, p.4764, 1997.

BOTELHO, R.V.; MÜLLER, M.M.L. Extrato de alho como alternativa na quebra de dormência de gemas em macieiras cv. Fuji Kiku. Revista Brasileira de Fruticultura, Jaboticabal, v.29, n.1, p. 37-41, 2007a.

BOTELHO, R.V.; PAVANELLO, A.P.; PIRES, E.J.P.; TERRA, M.M.; MULLER, M.M. L. Effects of chilling and garlic extract on bud dormancy release in Cabernet Sauvignon grapevine cuttings. American Journal of Enology and Viticulture, Davis, v. 58, p.402-404, $2007 b$.

BOTELHO, R.V.; PIRES, E.J.P.; MOURA, M.F.; TERRA, M.M.; TECCHIO, M.A. Garlic extract improves budbreak of the 'Niagara Rosada' grapevines on sub-tropical regions. Ciência Rural, Santa Maria, v.40, n.11, p.2282-2287, 2010.

BRADFORD, M.M. A rapid and sensitive method for the quantitation of microgram quantities of protein utilizing the principle of protein-dye binding. Analytical Biochemistry, Orlando, v.72, n. 1-2, p.248-254, 1976.

CALÒ, A.; TOMASI, D.; CRESPAN, M.; COSTACURTA, A. Relationship between environmental factors and the dynamics of growth of the grapevine. Acta Horticulturae, Wageningen, v. 427, p. 217-231, 1996.

CARVALHO, P.E.R. Espécies florestais brasileiras: recomendações silviculturais, potencialidades e uso da madeira. Colombo: EMBRAPA-CNPF; Brasília: EMBRAPA-SPI, 1994. 640p.
CREISSEN, G.P.; EDWARDS,E.A.; MULLINEAUX, P.M. Glutathione reductase and ascorbato peroxidase. In: FOYER, C.H.; MULLINEAUX, P.M. (Ed.). Causes of photooxidative stress and amelioration of defense systems in plants. Boca Raton: CRC Press, 1994. p.343-364.

DURIGAN, G.; FIGLIOLIA, M.B.; KAWABATA, M.; GARRIDO, M.A.O.; BAITELLO, J.B. Sementes e mudas de árvores tropicais. São Paulo: Instituto Florestal, 1997. 65p.

FERREIRA, D. F. Sisvar: a computer statistical analysis system. Ciência e Agrotecnologia, Lavras, v. 35, n.6, p. 1039-1042, 2011.

FREITAS, M. L. M.; SEBBENN, A. M.; ZANATTO, A. C. S.; MORAES, E.; MORAES, M. A. Variação genética para caracteres quantitativos em população de Gallesia integrifolia (Spreng.) Harms. Revista do Instituto Florestal, v. 20,n. 2, p. 165-173, 2008.

GOLDBACK, H.; THALER, C.; WÜNSCH, A. Decomposition of 14C- labeled cyanamide in Vitis vinifera cuttings. Journal of Plant Physiology, Stuttgart, v.133, n.3, p.299-303, 1988.

GÓTH, L. A simple method for determination of serum catalase activity and revision of reference range. Clinica Chimica Acta, Amsterdam , v.196, n.2-3, p.143-151, 1991.

IAPAR- Instituto Agronômico do Paraná. Carta climática do Paraná. Versão eletrônica. 2012. Disponível: $<$ http://www.iapar.br/modules/conteudo/ conteudo.php? conteudo $=677>$. Acesso em: 10 nov. 2012.

KISHINO, A.Y.; GENTA, W.; ROBERTO, S.R. Introdução: produção de uva no Paraná. In: KISHINO, A.Y.; CARVALHO, S.L.C.D.E.; ROBERTO, S.R. Viticultura tropical: o sistema de produção do Paraná. Londrina: Iapar, 2007. p.22-23.

KUBOTA, N.; MIYAMUKI, M. Breaking bud dormancy in grapevines with garlic paste. Journal of the American Society for Horticultural Science, Alexandria, v.117, n.6, p. 898-901, 1992.

KUBOTA, N.; YAMANE, Y.; TORIU, K.Breaking bud dormancy in grape cuttings with nonvolatile and volatile compounds of several Allium species. Journal of the Japanese Society for Horticultural Science, Kyoto, v. 71, n. 4, p. 467-472, 2002. 
KUBOTA, N.;YASUSHI, Y.; KOJI, T.; KAZUYOSHI, K.; TESUO, H.; SHOJI, N. Identification of active substances in garlic responsible for breaking bud dormancy in grapevines. Journal of the Japanese Society for Horticultural Science, Kyoto, v. 68, n.6, p.1111-1117, 1999.

LEVER, M. A new reaction for colorimetric determination of carbohydrates. Analytical Biochemistry, Orlando, v. 47, n. 1, p.273-279, 1972.

LUSSO, M.F.G.; PASCHOLATI, S.F. Activity and isoenzymatic pattern of soluble peroxidases in maize tissues after mechanical injury or fungal inoculation. Summa Phytopathologica, Botucatu, v. 25, n. 3, p. 244-249, 1999.

MULLINS, M. G.; BOUQUET, A.; WILLIANS, L. E. Biology of the grapevine. New York: Cambridge University Press, 1992. 239p.

NIR, G.; SHULMAN, Y.; FANBERSTEIN, L.; LAVEE, $\mathrm{S}$. Changes in the activity of catalase in relation to the dormancy of grapevine (Vitis vinifera L.) buds. Plant Physiology, Rockville, v.81, n.4, p. 1.140-1.142, 1986.

NOGUEIRA, J.C.B. Reflorestamento heterogêneo com essências indígenas. São Paulo: Instituto Florestal, 1977. 71p. (Boletim Técnico, 24).

OMRAN, R.G. Peroxide levels and the activities of catalase, peroxidase, and indoleacetic acid oxidase during and after chilling of cucumber seedings. Plant Physiology, Rockville, v.65, n.2, p.407-408, 1980.

OR, E.; VILOZNY, I.; EYAL, Y.; OGRODOVITCH, A. The transduction of the signal for grape bud dormancy breaking induced by hydrogen cyanamide may involve the SNF-like protein kinase GDBRPK. Plant Molecular Biology, Netherlands, v. 43, n.4, p. 483-494, 2000.

PINTO. M.; LIRA, W.; UGALDE, H.; PÉREZ, F. Fisiologia de la latência de lãs yemas de vid: hipótesis actuales. Santiago de Chile: Facultad de Ciências Agronómicas, 2012. 16p. Disponível em: <http//agronomia.uchile.cl/extension/ serviçosproductos/giel/publications $>$ Acesso em: 24 dez. 2012.

PINTO M, LIRA W, UGALDE H, PÉREZ F; Fisiologia de la latência de lãs yemas de vid: hipótesis actuales. Grupo de Investigación Enológica (GIE). Universidad de Chile, Facultade de Ciências Agronómicas, Santiago, Chile. 16p. Disponível em: $<$ http//agronomia.uchile.cl/extension/serviçosproductos/giel/publications $>$ Acesso em 24 Dez. 2007.
SANCHEZ, E.S.; Evaluación del extrato de ajo como estimulador de la brotación en ciruelo japonés, Prunus salicina L. 'Santa Rosa'. 1992. 63F. Dissertação (Mestrado em Fruticultura) - Colegio de Postgraduados, Centro de Fruticultura, Texcocco, 1992.

SCANDALIOS, J.G. Regulation and properties of plant catalases. In: FOYER, C. H.; MULLINEAUX, P. M. (Ed.). Causes of photooxidative stress and amelioration of defense systems in plants. Boca Raton: CRC Press, 1994. p.275-315.

SETTIMI, L.; DAVANZO, F.; FARAONI, MICELI, G.; RICHMOND, D.; CALVERT, G.M. Update: Hidrogen Cyanamide-related Ilnesses-Italy, 20022004. Morbidity and Mortality Weekly Report, Atlanta, v.54, n. 16, p.405-408, 2005.

SHULMAN, Y.; NIR, G.; LAVEE, S. Oxidative processes in bud dormancy and the use of hydrogen cyanamide in breaking dormancy. Acta Horticulturae, The Hague, v.179, p.141-148, 1986.

SIMEPAR - Instituto Tecnológico de Sistema Meteorológico do Paraná. Centro Politécnico da UFPR - Curitiba - Paraná - Brasil, 2012.

TOMÁNKOVÁ, K.; LUHOVÁ, L.; PETŘIVALSKÝ, M.; PEČ, P.; LEBEDA, A. Biochemical aspects of reactive oxygen species formation in the interaction between Lycopersicon spp. and Oidium neolycoper- sici. Physiological and Molecular Plant Pathology, v.68, n.1-3, p.22-32, 2006.

VARGAS-ARISPURO, I.; MALDONADO, C. C.; TELLEZ, M. A. M. Compounds derived from garlic as bud induction agents in organic farming of table grape. Chilean Journal of Agricultural Research, Santiago de Chile, v.68, n.1, p. 94-101, 2008.

WANG, S.Y.; JIAO, H. J.; FAUST, M. Changes in the Activities of Catalase, Peroxidase, and Polyphenol Oxidase in Apple Buds During Bud Break Induced by Thidiazuron. Journal Plant Growth Regulation, New York, v.10, n.1-4, p.33-39, 1991. 